\title{
Research on the Translation Intersubjectivity in the New Period
}

\author{
Li Lei \\ lecturer , Foreign language department of Henan University of TCM \\ Henan,China \\ E-mail: huiyitougao2015@163.com
}

Project "under the international spread of cultural background in medicine Translation Talents Training Path" (ID: 2014BYY021);

Henan College of Education Reform Project, "based on multi-modality medical English teaching mode network platform research" (ID:

2014JX33)

\begin{abstract}
Interactive Subjectivity is the main issue raised in the reflection and aimed at correcting the " $I$ " as the absolute subject. As to the others, it is an absolute object dualism of opposition thinking. The so-called Translation Intersubjective mainly refers to the practice of translation subject and other subjects in a relationship of equality in interactive performance of subjectivity, including translation between subjectivity and the body of an equal relationship of the two personality interactive content; it is to translator, author, or reader as the center of correction and supplementary individual subjectivity. Characteristics of intersubjectivity theory are: diversity, equality and integrity. Wherein differences and equality between one another proof, mutually complementary relationship, and integrity is more macro and command of a way of thinking. Intersubjectivity of Translation Studies is mainly reflected in the following three aspects: first, intersubjectivity helps establish normal relations between subjects of ethics; second, to help solve translation problems; third, intersubjectivity helps to enhance translation experiences.
\end{abstract}

Key words: translation; interactivity; subjectivity; significance

\section{RESEARCH ON THE TRANSLATION SUBJECTIVITY}

Translation and conversion regardless of the language from the narrow to the broad knowledge and cultural exchanges, and promote the activities participated. Even the machine translation must rely on people to collect corpus and preparation procedures. Moreover, machine translation proofread and relies on bilingual people to complete. Who is the subject of translation; human subjectivity, the starting point was undoubtedly the translation of theoretical discussion and destination.

\section{A. The Translators' Subjectivity and Consciousness}

The complex communicative activities, the translators' role is vital, irreplaceable. However, in the historical process development of the translation, the lack of identity and status of the translator have long recognized and valued. In the thoughts and the impact of cultural translation turn modernism which include deconstruction, hermeneutics and cultural control, and also this situation gradually changed. Hermeneutics also believe that is not a present but also really the author's intention, the interpreter does not have to stick to the original author identity, but should focus on issues of concern to the text. Although a work of each word, words, sentences will not change, but its meaning in the passage will be read by different audiences and also it is constantly changing. Deconstruction and hermeneutics or even eliminate the difference between the original and the translation. Because language is a series of uninterrupted chain of meaning, each of the original text is not absolute, but permeated with the previous mark of text that all texts are intersexuality. Everything is understood translation: the certain so-called original translation is just earlier than it appears which does not have the advantage of originality and authority.

In short, the impact of science and culture together under study changed with the main problem of consciousness translator unprecedented attention. The text has unlimited openness; Hermeneutics is understood that all translation culture school of thought is the translator of the original rewrite in a particular historical, social or cultural context. These theories and ideas have greatly improved the status of the translator's subjectivity publicity.

\section{B. The Scope and Limits of Translation Subjectivity}

Initiative is the most significant Subjective features. Initiative means that a person purpose of understanding the world and transform the world of activities planned and proactive activity. Due to the different growth environment and educational background, each translator has a very strong personal touch in cultural beliefs, values, and ways of thinking and other aspects of aesthetic taste. Subjectivity is not equal to the creativity, subjectivity. Plays are limiting factors, have preconditions. Passivity is the second important feature of subjectivity. Because the translator is a translation activity in the most active subject, subjectivity to other subjects must reflect the impact of subjectivity through the translator, the main constraints of the translation discussion are mostly concentrated on the limits of the translator subjectivity.

\section{THE CHARACTERISTIC OF TRANSLATION INTERSUBJECTIVITYT}

Translation Context connotation corresponding translation in interactive body under intersubjectivity has differences, equality and integrity of the three features. Because there are differences, they produced demands for 
equality; respect for differences is true equality. Equality is equality of personality, each subject in the impossible position and interests mean absolute, we can only maintain a dynamic balance. Small text, large social and cultural should seek to develop the basis mutual respect for differences, the pursuit of harmony, cooperation and development are as a whole.

\section{A. Difference}

Translation based on the language and cultural differences. Respect and reflect differences in the translation should also be timeless appeal. Subject to the traditional philosophy guided translation theory attempts to somehow strong culture as a universal truth, and their differences in unified other cultures are to make the world move towards it as the center of the same. Author-centric translation theory of primitive cultural paradigm tries to cover the target language culture to the reader or translator, as the center of translation theory, paradigm attempts to interpret language culture digestion primitive culture. These are based on obliterate differences, not including "otherness" on the basis of thinking, to replace the one-sided approach with an individual centrism. Translation fundamental purpose is to nourish itself through alien, which is bound to break cultural or ethnocentric dream to maintain their cultural purity. Strong xenophobic and exclusive behind his actions is a cultural narcissism, is not conducive to cultural exchange and enrichment development of the family culture. From another perspective, the translator must guard against the phenomenon of cultural colonization. If you pay attention to retain our national culture character and dignity of laissez-faire ideology of alien cultures and values eroded, we may eventually lose the national culture of independence and autonomy.

\section{B. Equality}

Translation is a relationship involving the practice of social interaction between people; it aims to promote inter-cultural exchanges among different ethnic groups and different languages. Communication activities are often the ultimate goal is to reach a consensus opinion. Translation is not only a reproduction of the original author's intent, it is not only linguistic signs, and it is not only to achieve some purpose to rewrite. From a broader perspective, it should be the creation, translation, reading and evaluation process are taken into account, and it is a cross-cultural communication containing the activities of the main complex relationships. Participant's translation of the original author, the translator, the target reader, commentators and translations instigator should participate in the main character equal translation activities, and play this interactive relationship subjectivity, and this subjectivity in the interactive relationship of equality is intersubjectivity.

\section{Holistic}

Relative to the whole part, it is a broader focus, broader perspective. Research focus on the intersubjectivity of the "people", and do not want to see a single and individual person. The difference between self and otherness is relative difference between subject and object. Self and other, subject and object, which form a "you have me, I have you." In the process of transformation of the individual subject, the "people" is no longer an individual person, but "the sum total of social relations." In each individual it is hidden behind a complex network of relationships that belongs to culture and society. Communications between people and people are actually cultural exchanges and social relations, which is the epitome of the latter conflict and integration. As a social interaction, the translation is not a simple, neutral language and information conversion behavior, but with the factor of ideology, culture and customs, economic factors, political struggle and so on.

\section{THE TRANLATION STUDIES OF INTERSUBJECTIVITY}

Philosophy can provide theoretical guidance for other disciplines. "Translation problems can be seen more clearly from the standpoint of philosophy. More importantly, translate research and development will change the discourse and allow the emergence of new insights and use interdisciplinary research methods to break the plight of the rigid terms and concepts cause. "Philosophical Thoughts can provide fresh ideas for translation studies, but also conducive to enhancing Theory of Translation Studies.

\section{A. Intersubjectivity helps to build Normal ethical relationship between subjects}

Intersubjectivity ethics contribute to the establishment of normal subjects' relations. With the continuous development of science and technology, economic and cultural should enhance cooperation and exchanges. Translation can affect the range more widely, and the role played by growing, corresponding to assume responsibility for the translator, which also is a more and more interwoven network of relationships with other participants increasingly complex. Translation is no longer a personal act, it is not only to be translated from the original language of symbol conversion, and it is a cross-cultural social behavior, involving interaction between subjects. Between the language and the complex relationship, culture and interpersonal call translation researchers ponder the ethical level. Firstly, intersubjectivity can provide theoretical support for normal philosophical ethics between people. Self and others are to experience the same way as each other: the self to the experience of others with respect to the others, me, and others to put my experience to others with respect to him. Self is the "I" of the self, but also others of others. Secondly, from the perspective of intersubjectivity explore ethical issues in translation of each body and multilevel nature of translation ethics grasp on the whole, it can make healthy further development of translation ethics. Intersubjectivity is concerned that people was the main premise of intersubjectivity, mutual recognition in exchange activities, mutual respect, independence, mutual checks and balances. After all, the ethical issues are also interpersonal relations.

\section{B. Intersubjectivity helps to solve translation problems}

Intersubjectivity can help translate research work out the predicament caused by the Dualism. If we look at the 
interactive thinking subjectivity in translation doctrine of structuralism and deconstructionism relationship genre, you might get a different understanding. First, the rise of deconstruction really allows us to see the structure of theories which are still insufficient places. Because the cut off contact is with the outside things, getting rid of the last of the research method, structuralism separates the link between language and culture, society, history and other factors. Structuralism emphasize the significance of translation theory from the relationship between language inside each symbol, which not only denies the original author to the original significance of the role, but also denied the reader or the translator as a subject involved in understanding the initiative. Secondly, the deconstruction of structuralism criticism and reflection is a digestion-style criticism and deconstruction by the use of logic and thinking in many ways of structuralism. Deconstruction has a large subversive and destructive criticism, based on the order that do not destroy the original reconstruction of the new order, nor to translate new methodology. Deconstruction here is conflicting thoughts. On the one hand, too much emphasis on the significance of the uncertainty, the authority to overthrow the original, emphasizing the importance of the reader, completely negates faithful translation. On the other hand, deconstructionist can advocate alienation and translation strategies.

\section{Intersubjectivity helps to enhance translation experiences}

Currently, many researchers see a positive role of intersubjectivity theory of translation studies, dedicating to the applied translation theory. Like any theory, intersubjectivity theory here is a gradual maturation process. Within a century, it has undergone epistemology ontology - Essay - Practice development process. In the main body of the philosophy of object-raising activities are characterized. The subjects were objectified; objective reality of the task is to obtain the main objective understanding of the object and then questioning the objective truth of this world. Regression is not to abandon the practice of translation theory thinking. Only that translation studies should be starting from the actual translation behavior, found problems, summary cause of the problem, and rose to ponder the theoretical level in order to describe the phenomenon of translation and practice of translation guide better. Emphasize the living world language is not to deny the existence of linguistic meaning in theory. Just practice attribute to translation activities require us to see the language in the practical application of change and development. In addition, language studies and cultural studies in translation are not mutually exclusive and binary oppositions. In fact, the language translation process includes cultural ideology and other factors.

\section{REFERENCE}

[1] Tan Fang, Huang set Criticism and Construction - Inter-subjectivity of Translation [J] Beijing International Studies University .2011 (10)

[2] Tanggui Xin Fu Lei and Romain Rolland - translator and author, cross-cultural perspective of research $[\mathrm{J}]$ Between Subjects of Translation of Southwest University for Nationalities (Humanities and Social Sciences) .2011 (S2).

[3] Hua Youjie Functional Translation Theory in the body and between the body of phenomenology Dynasty [J]. Chongqing University of Science and Technology (Social Science Edition) .2011 (14)

[4] Chang Hui, Huang set. Translating "inter-subjectivity" dialectical understanding [J]. Foreign Language Research .2011 (03)

[5] Cai cases of Lee, Shen Lianyun show his person: the translator between the subjectivity of the ethical mission $[\mathrm{J}]$ Hebei Polytechnic University (Social Science Edition) .2011 (02).

[6] Huang Pei true. On the Intersubjectivity translation activities of [J]. Hanshan Teachers College .2011 (01)

[7] Ma Xiaohui, Meng new trend intersubjectivity in the 20th Century Western Philosophy Development [J]. THEORY .2011 (01)

[8] Expounded, under Panjin Hao. Communicative Action Theory Intersubjective translation $[\mathrm{J}]$. Inner Mongolia Agricultural University (Social Science Edition) .2010 (06)

[9] Lijia Bo Inter subjectivity of translation [J]. Puyang Vocational and Technical College .2010 (05)

[10] Wu Hualing Sexual explore the subject between Lin translation [J]. Xianning College .2010 (10) 